\title{
Corporate Governance and Audit
}

\author{
Suzana Guxholli \\ Economic Advisor, Prime Minister’s of Albania Cabinet, Tirana, Albania \\ Vjollca Karapici \\ University of Tirana, Tirana, Albania \\ Albana Gjinopulli \\ Ministry of Finance, Tirana, Albania
}

\begin{abstract}
According to statistics during 2007, public expenditure in Albania exceeded 360,000 million Albanian Lek. How this money is spent and the quality of services it provides is critically important to us all as users of services and as taxpayers. Because of that we all need governance of our public services to be of a high standard. The main aim of this paper is to show how good governance leads to good management, good performance, good stewardship of public money, good public engagement and, ultimately, good outcomes. Under such situation, corporate governance is being examined more closely than ever before. Media coverage of corporate crises increasingly focuses on the highest management; what are mangers doing and do the relationships they have with the company weaken the effectiveness of their oversight? In this paper the authors have utilised standard research methods of questionaries collecting data from to 120 internal audit units in different organisations in Albania. Findings of the study indicates that: There is clear evidence that many managers have difficulties in fulfilling their responsibilities. To help them with their tasks, there is an urgent and ongoing need to be clear about the purpose of governance and the role of the governor, expand the supply of governors, improve induction programs and encourage good relationships between governors and the executive teams who are accountable to them. Internal auditors, by having an objective view from inside the organization, can play a vital role in the governance process by keeping management, the board, and external auditors aware of risk and control issues and by assessing the effectiveness of risk management. Effective corporate governance requires a system of checks and balances, assuring that the right questions get asked of the right people. An effective system of corporate governance will establish a link among management, the board, the external auditor, and the internal auditor in a way that creates a structure (with incentives and disincentives) that enables people with overlapping but not entirely congruent interests to have a sufficient level of confidence in each other and the organization as a whole. As result of a changing governance environment, the role of auditors is increased. They must continue to monitor such changes and evaluate how they impact the role of internal auditors in the future. Internal auditors also should be encouraged to seek different tools,
\end{abstract}

Suzana Guxholli, Ph.D., Economic Advisor, Prime Minister's of Albania Cabinet.

Vjollca Karapici, Professor of Financial Analysis and Auditing, Accounting Department, Faculty of Economics, and Business, University of Tirana.

Albana Gjinopulli, MPA, Head of Unit, Methodology and Training, Central Harmonization Unit for Internal Audit, Ministry of Finance.

Correspondence concerning this article should be addressed to Suzana Guxholli, Prime Minister’s Office, Rr. Bulevardi Deshmoret e Kombit, Tirana, Albania. Email: suzana.guxholli@km.gov.al; guzana2002@yahoo.ca. 
resources, and best practices. Internal audit plays a pivotal role in this process by fostering an integrated, well-planned, and progressive governance program

Keywords: corporate governance, convergence, audit committees, governance codes, risk control, internal audit, governance program

\section{Corporate Governance and the Role of Auditing}

\section{Corporate Governance}

Corporate governance is the system by which companies are directed and controlled. Boards of directors are responsible for the governance of their companies. The shareholders' role in governance is to appoint the directors and the auditors and to satisfy themselves that an appropriate governance structure is in place. The responsibilities of the board include setting the company's strategic aims, providing the leadership to put them into effect, supervising the management of the business, and reporting to the shareholders on their stewardship. The board's actions are subject to laws, regulations, and the shareholders in general meeting (United Kingdom) ${ }^{1}$

Internal auditing. Internal auditing is an independent, objective assurance and consulting activity designed to add value and improve an organization's operations. It helps an organization accomplish its objectives by bringing a systematic, disciplined approach to evaluate and improve the effectiveness of risk management, control, and governance processes. ${ }^{2}$

Governing body. The body with overall responsibility for directing and controlling an organization.

Governance has become a hot topic as evidence mounts on the critical role it plays in determining societal well-being. Not surprisingly, governance as a term has progressed from obscurity to widespread usage, particularly in the last decade. "Good governance is perhaps the single most important factor in eradicating poverty and promoting development”- stated ex Secretary General of UN Kofi Annan. ${ }^{3}$

The topic of organizational governance (often referred to a corporate governance) is important for many key stakeholders in the political and business worlds. Typically, auditors operate in two capacities in this area. First, auditors provide independent, objective assessments on the appropriateness of the organization's governance structure and the operating effectiveness of specific governance activities. Second, they act as catalysts for change, advising or advocating improvements to enhance the organization's governance structure and practices. By providing assurance on the risk management, control, and governance processes within an organization, internal auditing is one of the key cornerstones of effective organizational governance. This paper will introduce the concept of the importance corporate governance and auditing in its assurance and advisory role with regard to specific aspects of organizational governance. Corporate governance is a complex topic that overlaps with other audit subjects. Various companies, governments, research organizations, regulatory bodies, and other organizations have addressed aspects of the broad topic of corporate governance through various means.

The concepts outlined in this paper are intended to point to the role of audit (without differentiating between external and internal), methods by which those roles can be fulfilled and the essential ingredients necessary to

\footnotetext{
${ }^{1}$ Report of the Committee on the Financial Aspects of Corporate Governance (Cadbury committee), December 2002.

2 IIA Standards.

${ }^{3}$ Kofi Anan, Retrieved from www.unu/p\&g/wgs.
} 
support an effective audit function.

\section{What Is Corporate Governance?}

Exactly what is governance? More specifically, what is corporate governance, and how can an internal auditing activity be used to improve corporate governance?

Definitions can be challenging, subtle, complex and powerful. Let begin by the definition of what governance is not: Governance is not synonymous with government. This confusion of terms can have unfortunate consequences. A public policy issue where the heart of the matter is a problem of "governance" becomes defined implicitly as a problem of "Government", with the corollary that the onus for "fixing" it necessarily rests with government.

Since governance is not about government, what is it about?

We frequently use the term corporate governance and many of us understand that one of the main responsibilities of boards is to ensure that the governance processes are effective; however, the term is rarely defined.

Partly it is about how governments and other organizations interact, how they relate to citizens, and how decisions are taken in a complex world. Thus governance is a process whereby societies or organizations make their important decisions, determine whom they involve in the process and how they render account. Since the process is hard to observe students of governance tend to focus our attention on the governance system or framework upon which the processes rest, that is the agreements, procedures, conventions or policies that define who gets power, how decisions are taken and how accountability is rendered.

Corporate governance means the process and structure used to direct and manage the business and affairs of the corporation with the objective of enhancing shareholder value... The process and structure define the division of power and establish mechanisms for achieving accountability.

There is no single, comprehensive, universally accepted definition of organizational governance. However, certain common elements are present in most definitions of organizational governance that describe it as the policies, processes, and structures used by organizations to direct and control its activities, achieve its objectives, and protect the interests of its diverse stakeholder groups in a manner consistent with appropriate ethical standards.

An often-used definition of organizational governance comes from the Paris-based forum of democratic markets, the Organization for Economic Co-operation and Development (OECD, 2004):

Corporate governance involves a set of relationships between a company's management, its board, its shareholders and other stakeholder. Corporate governance also provides the structure through which the objectives of the company are set, and the means of attaining those objectives and monitoring performance are determined.

This structure should be a system of checks and balances designed to permit the appropriate scope of authority (power) and limit the abuse of that authority (accountability). Effective corporate governance is based upon strong working relationships among four groups: management, the board, external auditors, and internal auditors. Internal auditing is integral to good corporate governance. The internal audit activity's unique fulltime focus on risks and controls is vital to a sound governance process. Take, for example, WorldCom, where the internal auditor, who called the matter to the attention of the audit committee chairman after the then-chief 
financial officer resisted taking corrective action, discovered \$ 3.8 billion of dubious accounting. The need for internal auditing as an element of corporate governance has never been more clearly demonstrated than by recent events.

Financial reporting is not the only important responsibility of boards. Other areas relating to safeguarding of corporate assets, operational efficiency and economy, and compliance with rules, regulations, and policies are also extremely important. While effective internal controls are management's responsibility, it requires the participation of everyone in an organization, the board, management, external auditors, and internal auditors to be effective. Given the current environment it is surprising that management would choose to operate without internal auditing. All organizations should have a fully resourced, independent internal auditing activity that is professionally staffed and chartered to evaluate the risk management, control, and governance processes.

\section{Role of Auditing in Governance}

Auditing typically operates in two capacities. First, auditors provide dependent, objective assessments on the appropriateness of the organization's governance structure and the operating effectiveness of specific governance activities. Second, they act as catalysts for change, advising or advocating improvements to enhance the organization's governance structure and practices.

In an organization, management and the board establish and monitor companywide systems for effective governance. Internal auditors can support and improve these actions. In addition, although auditors should remain independent, they may participate in the establishment of governance processes. By providing assurance on the organization's risk management, control, and governance processes, auditing becomes a key cornerstone for effective organizational governance.

Which capacity is most relevant for auditing is highly influenced by the maturity level of the organization's governance processes and structure, and the organizational role and qualification of auditors. In an organization with a less mature governance structure and process, the internal audit function may be focused more on advice regarding optimal structure and practices, as well as comparing the current governance structure and practices against regulations and other compliance requirements. In organizations with more structured and mature governance practices, auditors and specifically internal auditors could focus more on:

- Evaluating whether companywide governance components work together as expected;

- Analyzing the level of reporting transparency among parts of the governance structure;

- Comparing governance best practices;

- Identifying compliance with recognized and applicable governance codes.

Internal auditing will often be most effective in dealing with governance activities by doing more than performing discrete audits of specific processes. An internal auditor's unique position in an organization allows him or her to observe governance structure and design, while not having direct responsibility for them. Often, internal auditors can assist organizations better by advising the board of directors and executive management on needed improvements and changes in structure and design, not just whether established processes are operating. This is different, however, from providing objective assessment of specific governance activities through discrete audits. Ultimately, internal audit assessments regarding governance activities are likely to be based on information obtained from numerous audit assignments over a period of time. Optimally, internal auditors should 
aim to provide assessments on the effectiveness of key organizational governance elements, either separately from, or combined with, assessments on the effectiveness of risk management and key controls. These governance activity assessments should take into account: specific governance assignments, the results of specific board-level governance review work, governance issues arising out of myriad audit assignments performed during a specific period of time, other information available to or known by the internal auditor.

Internal auditors may operate most effectively for the board as an agent of the board who provide independent, objective information and evaluation. Internal auditors can inform the board on matters such as culture, tone, ethics, transparency, and internal interactions. In addition, contemporary internal auditing is based on the organization's framework for identifying, responding to, and managing the different strategic, operational, financial, and compliance risks facing the organization.

\section{Specific Activities of Organizational Governance}

Governance activities exist to help the organization meet its objectives in being well-run and accountable to its stakeholders. Just like in any other activity, management and the board will want to articulate their objectives in each area and put in place programs to achieve those objectives. The following sections provide suggestions of the objectives and programs related to different governance activities. Recognizing the significant overlap between governance activities and other organizational initiatives, this document focuses on the tasks that are not typically associated with other initiatives.

There are other common elements of effective governance in organizations.

The IIA's definition of internal auditing refers to “... bringing a systematic, disciplined approach to evaluate and improve the effectiveness of risk management, control, and governance processes”. This definition incorporates the broad advisory and assurance role that internal auditing can have regarding an organization's governance processes.

The internal audit activity should assess and make appropriate recommendations for improving the governance process in its accomplishment of the following objectives:

- Promoting appropriate ethics and values within the organization;

- Ensuring effective organizational performance management and accountability;

- Effectively communicating risk and control information to appropriate areas of the organization;

- Effectively coordinating the activities of and communicating information among the board, external and internal auditors, and management.

Internal auditors can perform specific tasks that assist organizations in regard to governance structure and processes, and should consider assisting management and the board by assessing the following areas:

Board structure, objectives, and dynamics. The board and its committees should be appropriately structured and chartered to operate effectively. There should be healthy board and management interaction; adequate board meeting time devoted to open discussion; a full range of issues considered at board meetings; appropriate board composition (e.g., number of board members, absence of conflicts of interest, capabilities of board members); sufficient frequency of meetings; and meetings in private executive sessions. A board should devote sufficient attention to risks, the organization's risk appetite, and risk management practices. It is not commonplace for internal auditors to evaluate these topics. However, organizations and their boards should 
consider whether internal audit involvement would be beneficial and accepted.

Board committee functions. Internal auditors can review board meeting schedules, establishment of agendas, dissemination of advance information, and adherence to the committee charters. Internal auditors also can evaluate whether the board committees maintain a calendar of responsibilities and regularly monitor performance to published responsibilities.

The board policy manual. Internal auditors could assess the process of developing and maintaining the board governance policy or policy manual (or assist in these activities); evaluate compliance procedures; and make recommendations for improvement.

Processes for maintaining awareness of governance requirements. Governance obligations vary from country to country and industry to industry. Internal auditors could develop networks and processes to maintain awareness of governance requirements and evaluate and monitor the organization's processes for maintaining external awareness. Internal auditors also could interface with roundtables, professional trade associations, internal and external subject matter experts, and internal compliance or risk assessment committees. Auditors can assess whether the organization is in compliance with governance codes and specific criteria found in a governance code; if the entity in not in compliance, auditors can evaluate the impact and cause of the noncompliance. Internal auditors can assess the adequacy of the disclosures relating to the organization's governance system in its annual report.

Board education and training. Board members need ongoing education on the significant issues facing the organization, changing technology, and emerging risk areas. New board members frequently need education to prepare them properly for their new responsibilities. Internal auditors can assist the board in these efforts by providing development of training content, delivery of training, and administrative support. Alternatively, internal auditors could assess the adequacy of the education provided to board members compared to best practices from other organizations.

Proper assignment of accountabilities and performance management. Organizational governance responsibilities are assigned to different parties within the company, and each party is accountable for fulfilling its responsibilities. If critical responsibilities are not assigned or assigned to the wrong party, governance suffers. Internal auditors can review whether all the key responsibilities related to organizational governance have been assigned, assigned to the proper parties, and whether the performance management system and disciplinary action processes are effective.

Completeness of ethics policies and codes of conduct. Most organizations have ethics policies and codes of conduct that govern acceptable employees' behavior and represent a key part of the organization's governance structure. Internal auditors can assess whether their organization's policies and codes include appropriate subjects and guidance. A number of codes of conduct are available for comparison. Most contain sections addressing conflicts of interest; confidentiality; fair dealing; proper use of organization assets; compliance with laws, rules, and regulations; and reporting of illegal or unethical behavior.

Communication and acceptance of ethics policies and codes of conduct. To be effective, ethics policies and codes of conduct need to be communicated clearly to, and understood and accepted by, employees. Internal auditors can assess whether this communication is occurring and whether the information is understood by employees. Internal auditors can use surveys, interviews, and other means to determine the effectiveness of this 
communication process. Internal auditors can assess the effectiveness of the processes established to enable employees to communicate concerns they have regarding an inappropriate behavior to management or the board (e.g., a whistle-blower process). Internal auditors can also facilitate discussion of ethics topics and processes to resolve ethical issues.

Ethics investigations and related employee discipline. Violations of ethics policies or codes of conduct are investigated usually; if wrongdoing is substantiated, the involved employees are disciplined. Internal auditors can conduct these investigations or, alternatively, assess the adequacy of investigations performed by others. As part of this assessment role, internal auditors should consider whether the investigations were impartial, performed by competent personnel, supported adequately by pertinent facts, and concluded with appropriate actions by management personnel.

Management evaluation and compensation. Compensation of management is coming under increased scrutiny. The concern is over not just reported cash compensation, but also indirect forms: stock compensation programs, personal use of the organization's resources, and reimbursement of excessive expenses. Internal auditors could focus on the accuracy and completeness of information provided to the board, the judgment exercised by management when classifying indirect executive benefits, and adequacy of the board's attention to this topic.

Recruitment processes for senior management and board members. Internal auditors can review recruitment standards and policies and evaluate whether practices meet organizational objectives. Although internal auditors should not influence individual decisions, patterns or extended deviations can be reported to the board.

Employee training. Effective organizational governance will normally require employees to be trained on topics such as internal controls, ethics policies, disclosure and compliance requirements, and board policies. Internal auditors can assess the adequacy of this training, and its frequency, effectiveness, and impact.

Governance self-assessments. The board should perform or provide oversight for assessments of their performance, appropriateness of their charter, adequacy of their calendar, and other governance structures and activities. Internal auditors could assist the board in these responsibilities by facilitating data collection and reporting results to the board. Alternatively, internal auditors can assess the adequacy of these efforts, and their compliance with applicable regulations for reporting back to the board.

Comparison with governance codes or best practices. It is becoming more common for governments or stock exchanges to establish governance codes. These codes can include a wide range of topics such as financial reporting practices, organizational structure, and social responsibility. They range from being required practices of the organization to suggested best practices. Internal auditors can provide assurance that their organization is in compliance with these codes.

External communications. External communications include financial reports, press releases, and communication during crises. Internal auditors can assess whether the organization's stated strategies and objectives for reporting to stakeholders are being accomplished. The focus would include not only accuracy, but also full transparency, truthfulness, and timeliness.

Oversight of external auditors. Internal auditors can assist the board in their management of external auditors by evaluating external auditor performance, their relationship with management and ways of handling 
disputes, the extent of additional work outside the normal audit engagement, and fees. Involvement in this area is not likely to take the form of an audit; rather providing advice and support.

There is no one-size-fits-all method to optimizing organizational governance. Each organization must tailor an individual solution that considers industry, maturity, business strategy, capabilities, culture, and competitive position.

\section{Corporate Governance Principles: Who are the Players and Who Has the Influence?}

Good governance is a journey that begins with a broad, organizational perspective. Making steady progress requires committed senior leadership, integrated planning, coordinated execution, and constant monitoring. Monitoring is one area where internal audit can add significant value, and still be true to its mission, objectives, and standards. Internal audit's responsibilities are growing due to increased regulatory scrutiny as well as directives from organizational executives to strengthen controls and improve risk management. Increasingly, business leaders expect internal audit to play a more strategic - rather than merely tactical—role in the governance process. At a high level, corporate governance can be thought to have seven interrelated components: Board of Directors and Committees, Disclosure and Transparency, Business Practices and Ethics, Legal and Regulatory, Risk and Performance Management, Monitoring, and Communication.

\section{Commonly Identified Organizational Governance Principles}

Companies should establish and disclose the respective roles and responsibilities of board and management. Organizational governance is a broad concept.

Fundamental to any corporate governance structure is establishing the roles of management and the board:

Principle 1. Lay solid foundations for management and oversight. Companies should establish and disclose the respective roles and responsibilities of board and management.

Recommendation 1.1. Companies should establish the functions reserved to the board and those delegated to senior executives and disclose those functions.

Recommendation 1.2. Companies should disclose the process for evaluating the performance of senior executives.

Recommendation 1.3. Companies should provide the information indicated in the Guide to reporting on Principle 1.

The board and management should have a balance of skills, experience and independence appropriate to the nature and extent of company operation:

Principle 2. Structure the board to add value. Companies should have a board of an effective composition, size and commitment to adequately discharge its responsibilities and duties.

Recommendation 2.1. A majority of the board should be independent directors.

Recommendation 2.2. The chair should be an independent director.

Recommendation 2.3. The roles of chair and chief executive officer should not be exercised by the same individual.

Recommendation 2.4. The board should establish a nomination committee.

Recommendation 2.5. Companies should disclose the process for evaluating the performance of the board, its committees and individual directors. 
Recommendation 2.6. Companies should provide the information indicated in the Guide to reporting on Principle 2.

There is a basic need for integrity among those who can influence a company's strategy and financial performance, together with responsible and ethical decision-making which takes into account not only legal obligations but also the interests of stakeholders:

Principle 3. Promoting ethical and responsible decision-making companies should actively promote ethical and responsible decision-making.

Recommendation 3.1. Companies should establish a code of conduct and disclose the code or a summary of the code as to:

- The practices necessary to maintain confidence in the company’s integrity;

- The practices necessary to take into account their legal obligations and the reasonable expectations of their stakeholders;

- The responsibility and accountability of individuals for reporting and investigating reports of unethical practices.

Recommendation 3.2. Companies should establish a policy concerning trading in company securities by directors, senior executives and employees, and disclose the policy or a summary of that policy.

Recommendation 3.3. Companies should provide the information indicated in the Guide to reporting on Principle 3.

Meeting the information needs of a modern investment community is also paramount in terms of accountability and attracting capital. Presenting a company's financial and nonfinancial position requires processes that safeguard, both internally and externally, the integrity of company reporting:

Principle 4. Safeguard integrity in financial reporting. Companies should have a structure to independently verify and safeguard the integrity of their financial reporting.

Recommendation 4.1. The board should establish an audit committee.

Recommendation 4.2. The audit committee should be structured so that it:

- Consists only of non-executive directors;

- Consists of a majority of independent directors;

- Is chaired by an independent chair, who is not chair of the board;

- Has at least three members.

Recommendation 4.3. The audit committee should have a formal charter.

Recommendation 4.4. Companies should provide the information indicated in the Guide to reporting on Principle 4.

And provide a timely and balanced picture of all material matters:

Principle 5. Make timely and balanced disclosure. Companies should promote timely and balanced disclosure of all material matters concerning the company.

Recommendation 5.1. Companies should establish written policies designed to ensure compliance disclosure requirements and to ensure accountability at a senior executive level for that compliance and disclose those policies or a summary of those policies.

Recommendation 5.2. Companies should provide the information indicated in the Guide to reporting on 
Principle 5.

The rights of company owners, that is shareholders, need to be clearly recognized and upheld.

Principle 6. Respect the rights of shareholders. Companies should respect the rights of shareholders and facilitate the effective exercise of those rights.

Recommendation 6.1. Companies should design a communications policy for promoting effective communication with shareholders and encouraging their participation at general meetings and disclose their policy or a summary of that policy.

Recommendation 6.2. Companies should provide the information indicated in the Guide to reporting on Principle 6.

Every business decision has an element of uncertainty and carries a risk that can be managed through effective oversight and internal control.

Principle 7. Recognize and manage risk. Companies should establish a sound system of risk oversight and management and internal control.

Recommendation 7.1. Companies should establish policies for the oversight and management of material business risks and disclose a summary of those policies.

Recommendation 7.2. The board should require management to design and implement the risk management and internal control system to manage the company's material business risks and report to it on whether those risks are being managed effectively. The board should disclose that management has reported to it as to the effectiveness of the company's management of its material business risks.

Recommendation 7.3. The board should disclose whether it has received assurance from the chief executive officer (or equivalent) and the chief financial officer (or equivalent) that the declaration provided in accordance is founded on a sound system of risk management and internal control and that the system is operating effectively in all material respects in relation to financial reporting risks.

Recommendation 7.4. Companies should provide the information indicated in the Guide to reporting on Principle 7.

Principle rewards are also needed to attract the skills required to achieve the performance expected by shareholders.

Principle 8. Remunerate fairly and responsibly. Companies should ensure that the level and composition of remuneration is sufficient and reasonable and that its relationship to performance is clear.

Recommendation 8.1. The board should establish a remuneration committee.

Recommendation 8.2. Companies should clearly distinguish the structure of non-executive directors' remuneration from that of executive directors and senior executives.

Recommendation 8.3. Companies should provide the information indicated in the Guide to reporting on Principle 8.

Each principle is of equal importance.

\section{Participants and Roles}

There are, broadly speaking, five parties that participate in an organization's governance activities and each has specific responsibilities. 


\section{Role and Responsibilities.}

Board plays the following role:

- The focal point for all governance activities;

- Ultimately accountable and responsible for the performance and affairs of the organization, effective risk management practices, and establishing a risk appetite level;

- Oversees all organizational activities (e.g., risk management, strategic direction setting, compliance with laws, good business, and ethical practices), but does not have direct management of any of them;

- Establishes the "tone at the top" and implements best governance practices for organizational performance. Senior management which is under the oversight of the board and:

- Sets strategic direction and establishes an entity's value system;

- Provides assurance that risks are managed as part of a risk management process, operations are monitored, results are measured, and corrective actions are implemented in a timely fashion.

Operating management that:

- Deploys strategy, enforces internal control, and provides direct supervision for areas under its control;

- Accountable to executive management, and ultimately the board, for implementing and monitoring the risk management process and establishing effective and appropriate internal control systems.

Internal auditing which:

- Performs assessments to provide assurance that governance structures and processes are properly designed and operating effectively;

- Provides advice on potential improvements to governance structures and processes.

External auditing provides independent assurance on the financial statement preparation and reporting activities, in accordance with applicable standards, regulations and accounting principles.

The roles of the parties are separate, and the responsibilities of each role are different. Effective governance is diminished if role boundaries are not respected. Good governance results from effective synergy generated among the activities of these differing roles, while maintaining their separation.

\section{Organizational Initiatives Impacting Governance}

A number of different initiatives within organizations overlap with the area of governance. Additionally, there are organizational initiatives that primarily may be directed at operational or compliance concerns, but which nonetheless impact governance activities. The organization's core values and ethics are the foundation for all activities, such as:

Compliance with legal or regulatory requirements. Various requirements are imposed by stock exchanges, industry regulators (e.g., banks, insurance companies), legislative bodies (e.g., the U.S. Congress with the U.S. Sarbanes-Oxley Act of 2002), etc.. In these cases, organizations typically have responded by implementing certain structures and processes to ensure compliance. Often, responses to these requirements define the key elements of the governance structure (e.g., composition of the board, role of external auditors).

Internal control assessment and reporting. Internal controls help organizations ensure that management's strategies and directions are carried out, often to mitigate risk. Many organizations have robust activities to document, assess, and report on the adequacy of these internal controls using established control frameworks 
such as the Committee of Sponsoring Organizations of the Treadway Commission (COSO), Criteria of Control (CoCo), etc.. Elements of these frameworks clearly overlap with elements of governance, including the control environment, monitoring, and detailed control activities.

Enterprise risk management. Organizations face a variety of risks, and many organizations are evaluating the adequacy of their risk management processes. COSO issued a framework for understanding and evaluating an organization's ERM structures and activities. Adequate understanding and assessment of risk and the effective implementation and functioning of appropriate risk mitigation strategies are key elements of governance processes.

Quality initiatives. Initiatives for improving quality processes in an organization include International Standards Organization (ISO) certification, European Foundation for Quality Management European award, Six Sigma, and the Baldridge award model. The various means these initiatives use to measure the effectiveness of an organization overlap with many structural elements of governance.

Transparency and disclosure. Organizations commonly report financial results and information to key stakeholders and increasingly are reporting more than financial results. Reporting on social responsibility, efforts to preserve the environment and other social issues are becoming common. Communicating an organization's values regarding stewardship, management practices, employee relations, and other topics often shows an organization's culture and tone. The transparency of financial and non-financial disclosures to stakeholders is a key element of governance.

Governance structures and processes. Although many of the initiatives listed above overlap with the general concept of organizational governance, some aspects are unique to organizational governance. These often relate to management structure, organization oversight, actions taken to set the tone of the organization (e.g., disciplinary actions taken by the board or management against those who violate organizational values), and specific processes related to the activities of executive management and the board.

There are undoubtedly other initiatives and activities that support governance. Based on the organization, the methods of pursuing those initiatives, and interaction of initiatives within an organization, there is often significant overlap among the activities of the various initiatives. There is nothing inappropriate with this overlap, but internal auditors need to understand these overlapping objectives and activities, clarify how they impact organizational governance activities, and understand the assessment or consulting work they perform in these other areas before fully executing their organizational governance activities.

\section{Conclusions and Recommendations}

\section{Conclusions}

Management is counting on internal auditors more than ever to improve governance processes. Internal audit profession has many opportunities to become a strategic player in corporate governance in response to increased government regulations and management directives to strengthen controls and improve risk management. Internal auditing standards calls on auditors to evaluate and offer recommendations to improve governance processes and affirms their importance in risk management activities.

However, internal audit will always have the challenge of remaining independent and objective, yet being 
part of the organization. In this age of intense scrutiny over business motives and ethics, the last thing a company needs is a passive internal audit function. But no organization wants an internal auditor group whose only response to risk is to eliminate it entirely. There are risks in any business venture, and closing off all risks means no rewards. Internal auditing requires business knowledge, insight, good judgment and effective communications. Organizational governance is a complex topic that may take internal auditors into areas not previously explored. Some key considerations to keep in mind are:

- Management may not have formally considered governance matters as part of a larger organizational governance strategy. Before embarking on exploring the proper role of internal auditors related to governance, internal auditors may need to work with management to ensure there is a proper understanding and definition of the governance processes and structure in the organization;

- A key role of the board and management is the establishment of the organization's strategy. Internal auditors typically do not challenge these key strategic elements or whether the primary organization's strategy is appropriate for the key organization stakeholders. However, this does not mean the internal auditor must remain silent on all items related to strategy. It could be beneficial to the organization for internal auditors to make observations on major issues related to strategy implementation, key risks not adequately addressed by the strategy, conflicts among various strategy elements, or the impact of the strategy on the organization or its stakeholders;

- Internal auditors must be careful to consider not only the results of individual audit tasks in assessing organizational governance, but also the overall structure of governance within the organization. At times, each part may appear appropriate, but could present serious issues when combined. Internal auditors should be aware of the limitations of performing specific governance review procedures without also having considered the broader (e.g., board) governance processes. Many elements of governance are driven from the top, and internal auditors should consider a top down review of governance to ensure that designed processes are adequate and embedded effectively throughout the organization;

- The governance environment is changing rapidly in many countries and industries. The internal auditor must continue to monitor these changes and evaluate how they impact the role of internal auditors in the future. Auditing organizational governance requires skills and competencies that internal auditors may not possess. Before undertaking audits in the governance area, it is critical to ensure that internal auditors posses the relevant skills or obtain appropriate training. Internal auditors also should be encouraged to seek different tools, resources, and best practices.

An additional challenge is the increasing need organizations have to attract and retain experienced chief audit executives. More organizations are establishing internal audit functions while there are a limited number of experienced professionals to fill these positions in the short term. Staffing levels and expectations in internal audit departments are increasing so as to enable a more meaningful role in sustaining the governance process. There is increasing demand for seasoned, experienced advisers who have the ability to differentiate between various shades of gray. Consequently, auditors must also continue to increase their skill levels in order to add greater value, help strengthen governance, and improve company performance.

The biggest challenge facing companies and their auditors is there is no one-size-fits-all method to improve 
corporate governance. Each organization will be required to tailor an individual solution that considers industry, maturity, business strategy, capabilities, corporate culture, and competitive position. Since there is no quick solution for addressing this multifaceted challenge, keeping the focus on good governance over the long term will be an important challenge for most organizations.

\section{Recommendations}

Investors and other stakeholders value companies that anticipate problems and show evidence of strong internal oversight. Internal audit should be a champion in assessing opportunities where corporate governance can be strengthened and suggesting corrective action as needed. But, first, a definition to clarify the concept of governance:

Corporate governance is the systems and processes an organization has in place to protect the interests of and create value for its diverse stakeholder groups. The best governance addresses the needs of all stakeholders - shareholders, employees, customers, lenders, vendors, and the community — because all of these groups share a common interest in the perpetuation of the business. Well governed organizations recognize that satisfying all stakeholders' interests is compatible in the long run, vital for sustaining the organization and enabling it to prosper. Auditing the effectiveness of an organization's corporate governance systems, practices, and performance requires a reliable framework and methodology. Having an overview of governance trends and challenges internal auditors face, the management bears primary responsibility for ensuring effective governance.

Internal audit performs these critical roles in all aspects of corporate governance by:

- Supporting the audit committee in fulfilling its heightened responsibilities;

- Addressing disclosure and transparency objectives in annual audit plan;

- Reviewing the effectiveness of the organization's code of conduct, ethics policies, and whistle-blower provisions;

- Helping assess risks and gauge performance across the organization;

- Monitoring corporate governance activities and compliance with the organization's policies;

- Facilitating and enhancing communications with the chief operating officer, chief financial officer, chief information officer, and other oversight executives.

The rewards of improved corporate governance are not merely a greater sense of personal accomplishment or of company pride. Researchers, along with several other business and academic studies, have found a strong correlation between effective governance and profitable investment opportunities. Internal audit plays a pivotal role in this process by fostering an integrated, well-planned, and progressive governance program.

\section{References}

ASX Corporate Governance Council. (2003, March). Principles of good corporate governance and best practice. Retrieved from http://www.asx.com.au/about/pdf/ASXRecommendations.pdf

Bhattacharya, A. K. (2008). Business standard: Corporate governance and audit accoutancy. Retrieved from http://www.business-standard.com/india/news/corporate-governanceaudit/324694/

Broadley, D. (2006). Bank for international settlements, FSI seminar on corporate governance for banks. In Deloitte Auditing and Its Role in Corporate Governance. Hong Kong: Deloitte Touche Tohmatsu. 
Brown, L. D., \& Caylor, M. L. (2006). Corporate governance and firm valuation. Journal of Accounting and Public Policy, 25(4), 409-434.

Cadbury Committee. (2002, December). Report of the committee on the financial aspects of corporate governance.

Carmichael, J., \& Kaufmann, D. (2001, June). Public sector governance and the finance sector.

Collier, P., \& Zaman, M. (2005). Convergence in european corporate governance: The audit committee concept. Corporate Governance: An International Review, 13(6), 753-768.

Graham, J., Amos, B., \& Plumtre, T. (2003). Principles for good governance in 21-st century. Policy Brief No.15, August 2003 IIA Standards Kofi Anan. Retrieved from http://www.unu/p\&g/wgs

OECD. (2004). Principles of corporate governance (revised May 2004).

The Institute of Internal Auditors. (2006, November). The role of internal auditing in public sector governance. Professional guidance. 